\title{
Pensar la persona a través del tejido: una propuesta de interpretación a partir del ejemplo de los tejidos jalq'a (Bolivia)
}

\author{
Kimberley Raas ${ }^{1}$
}

Recibido: 26 abril 2021 / Aceptado: 6 de junio de 2021

Resumen. Este texto tiene como objetivo presentar una propuesta de interpretación para explorar de qué maneras se puede considerar que se identifica, presenta y constituye la persona, en términos sociales y ontológicos, a través del tejido en los Andes. Partiendo de la vestimenta tradicional jalq'a (Andes bolivianos) y su particular estilo de diseño tejido como ejemplo, propongo tres enfoques para contribuir a esta reflexión: presentando la vestimenta tradicional como distintivo étnico, prestando atención a las relaciones que se generan en torno a la elaboración del tejido, y considerando el uso de los tejidos como ropas que envuelven el cuerpo para formar a la persona como runa.

Palabras clave: Andes; runa; tejido; ontología.

\section{[en] Thinking the Person through Weaving: a Proposal for Interpretation Based on the Example of Jalq'a Weavings (Bolivia)}

\begin{abstract}
This text aims to present an interpretative proposal to explore in what ways the person can be considered to be identified, presented and constituted, in social and ontological terms, through weavings in the Andes. Using traditional Jalq'a clothing (Bolivian Andes) and its particular style of woven decoration as an example, I propose three approaches to contribute to this discussion: presenting traditional clothing as an ethnic distinctive, paying attention to the relationships that are generated around the practice of weaving, and considering the use of weavings as clothes that envelop the body to form a person as runa.
\end{abstract}

Keywords: Andes; runa; weaving; ontology.

Sumario. 1. Introducción. 2. Los jalq'a, la vestimenta como distintivo étnico. 3. La mujer tejedora, la elaboración del tejido. 4. Runa, el uso de la ropa como envoltura. 5. Consideraciones finales. 6. Referencias.

Cómo citar: Raas, Kimberley. 2022. "Pensar la persona a través del tejido: una propuesta de interpretación a partir del ejemplo de los tejidos jalq'a (Bolivia)". Revista Española de Antropología Americana 52 (1): 95-112. 


\section{Introducción ${ }^{2}$}

La vestimenta tradicional, así como el mundo textil, en términos generales, siempre ha sido un tema muy presente en la antropología andina; prestando atención, principalmente, a su proceso de producción y técnicas de elaboración, su papel en la economía doméstica y la organización social, sus rasgos plásticos y su significado artístico, cultural y ritual (p.ej. Gisbert et al. 1987; Silverman 1994; Arnold et al. 2007). Más recientemente, y en el marco de las reflexiones surgidas del denominado giro ontológico (Holbraad y Pedersen 2017), han aparecido otros enfoques en los estudios materiales que fijan el interés en la cosmología, entendiendo por esta, en la línea propuesta por Descola, un estilo específico de relación entre los diferentes seres humanos y no-humanos, que se define por "los lazos que estos existentes tejen entre sí, los afectos que unos ejercen sobre otros y el tipo de tratamiento que se imponen mutuamente" (Descola 2012: 446). A partir de este interés, se ha ido estableciendo una línea de investigación en la antropología de los Andes que se ha preocupado por el papel de los objetos materiales y las entidades no-humanas en la vida social, así como por su agencia o capacidad de actuar (Raas 2020: 97). Concretamente, explora cómo las múltiples subjetividades humanas y no-humanas se expresan en la conceptualización, la elaboración y el uso de los objetos, y cómo los objetos, a su vez, inciden en la definición y conformación de lo que se considera que es el ser humano ${ }^{3}$.

Este enfoque permite entender los objetos, y para lo que me interesa comentar aquí, el tejido, como algo más que un producto elaborado, y pensar en el mismo como un elemento que forma parte de ese mundo "[...] construido intrínsecamente en términos de relaciones" (Allen 2020: 218), en el cual participan tanto actores humanos como no-humanos, según la cosmología andina. Asimismo, traslada el interés por lo que el objeto, y en este caso el tejido, "es" o "representa" para las personas (su significado), a la cuestión por lo que este "hace" (Bray 2009: 359), es decir, por el desarrollo de su participación en la vida social según las categorías propias de las cosmologías locales. Situándome en esta línea de investigación, y a partir del ejemplo de los tejidos jalq'a de Bolivia ${ }^{4}$, propongo explorar de qué maneras se puede entender que el tejido contribuye a la formación de las personas en tres sentidos diferentes: como persona jalq'a, como mujer tejedora, y como runa ${ }^{5}$.

El nombre jalq'a hace referencia a un área cultural que se ubica en el centro-sur de Bolivia, al oeste y noroeste de Sucre, ocupando parte de los departamentos de Chuquisaca y Potosí. Está conformada por unas 35.000 personas de habla quechua, asentadas en comunidades campesinas y pequeños ayllus que se encuentran en su

2 Esta investigación ha sido financiada por el Ministerio de Universidades a través del Programa de Formación del Profesorado Universitario (FPU19/02019).

3 Para la antropología de los Andes podemos citar, a modo de ejemplo, los trabajos sobre las miniaturas de piedra de animales llamadas illas o inqaychus (Bugallo 2016; Allen 2020), los tejidos tradicionales (Arnold 2018a; 2020), las ruinas arqueológicas como las wak'as o las chullpas (Carlos 2015; Mannheim y Salas 2015), y los instrumentos musicales (Rivera 2018).

4 Si bien recurro a los tejidos jalq'a a modo de ejemplo para las reflexiones que siguen, este artículo no tiene la intención de ser descriptivo, sino de hacer una aportación interpretativa y reflexiva a los estudios textiles de esta región.

5 Runa es el término usado por los hablantes de quechua para referirse a uno mismo como "gente" o "persona" (Muñoz 2020a: 10). 
mayoría entre los 2.500 y $3.500 \mathrm{~m}$ de altitud, en un paisaje marcado por formaciones de roca sedimentaria multicolor, amplias laderas onduladas perfiladas por cañones fluviales y un gran número de cuevas, grutas y quebradas (Figura 1). Sus habitantes se dedican principalmente a la agricultura de autoconsumo y tienen pequeños hatos de ovejas, cabras, bueyes y burros. Por su origen multiétnico, proceso de etnogénesis reciente y la ausencia de estructuras socio-políticas comunes, los jalq'a no son considerados un grupo étnico en el sentido clásico de la palabra, si bien se autodefinen con este etnónimo y son así conocidos por los grupos vecinos (Cereceda et al. 1993: 5-10; Cereceda 2018: 501; Martínez 2018: 203).

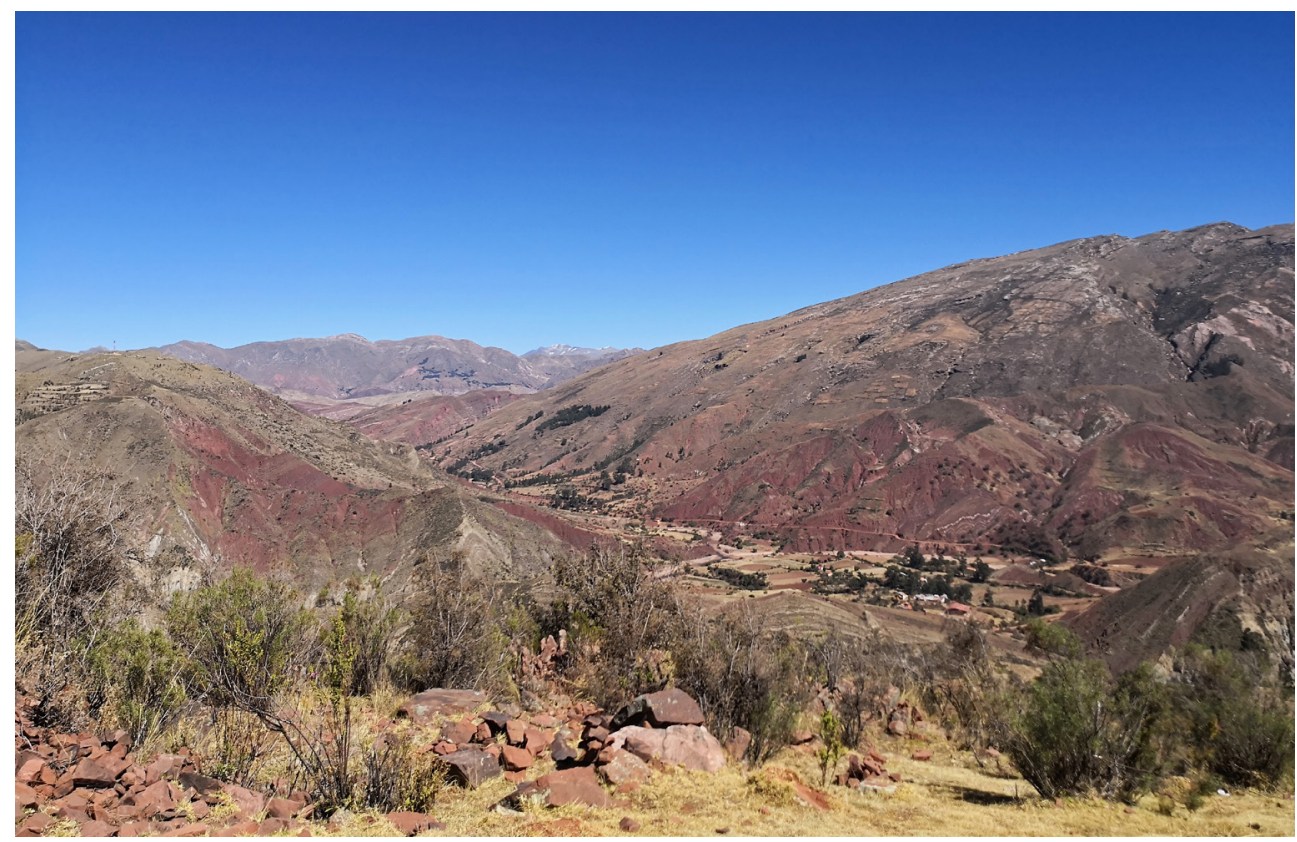

Figura 1. Paisaje de la región jalq’a, fotografía tomada en el camino entre Chataquila y Chaunaca (fotografía de la autora).

Particularmente, es el estilo de los diseños tejidos en las prendas que conforman su vestuario tradicional lo que más claramente define la identidad de estas comunidades (Cereceda 2018: 514). Son diseños abigarrados y confusos, sin contraste ni orden aparente, de rojos y negros bien intensos y con figuras de formas complejas que se confunden unas con otras y con el fondo (Figura 2). Las tejedoras se refieren a estos diseños como supay pallay, es decir, "diseños del demonio" o "espacio del demonio"; incluso las tejedoras de los grupos vecinos los reconocen así, llamándolos también pallay del $u k h u$ pacha, del "espacio profundo, inferior o interior" ${ }^{\text {. De }}$

6 El término quechua supay fue adoptado por la Iglesia para referirse al demonio cristiano (Cereceda 2019a: 353), mientras que pallay se refiere tanto a un diseño tejido (sustantivo), como a la acción de diseñar y elegir los hilos de un diseño tejido (verbo). Ukhu pacha, por su parte, es un término compuesto a partir de las palabras $u k h u$, que significa interior o, como partícula de posición, dentro o adentro, y pacha, noción compleja y amplia que significa tanto tiempo como espacio, aunque también se traduce como ropa y suelo. 
hecho, las tejedoras jalq'a reconocen al diablo y al infierno como inspiración de las imágenes que tejen (Cereceda 2018: 502, 2019a: 354).

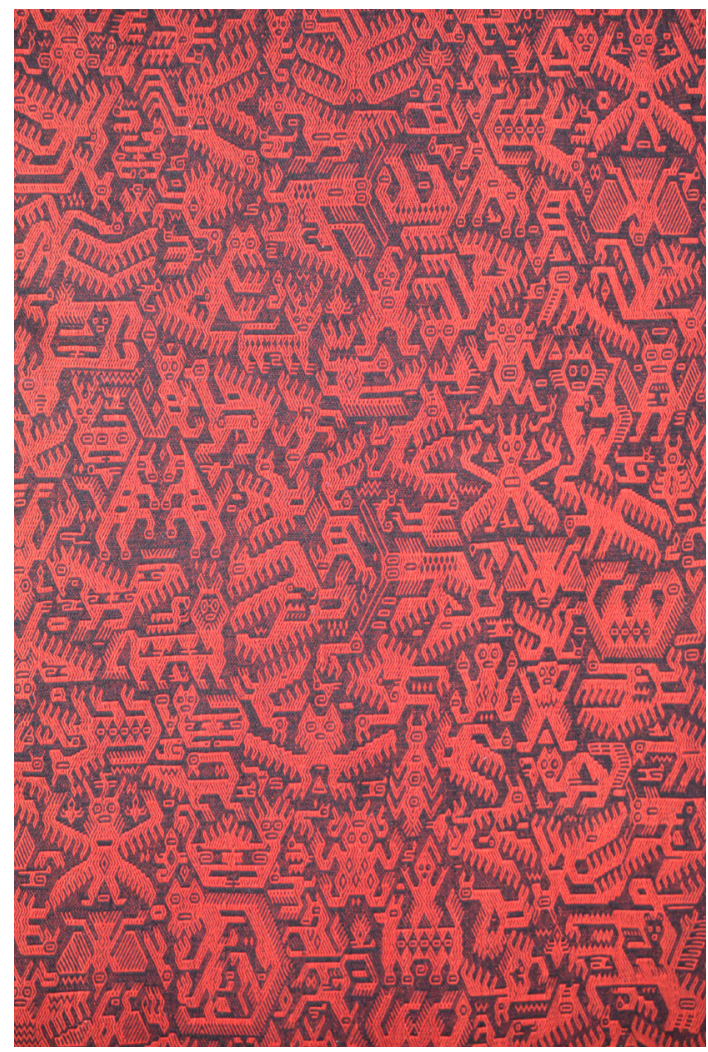

Figura 2. Supay pallay jalq’a (fotografía de Tatiana Aguirre).

Aunque decoran muchas de las prendas del vestuario tradicional, se desarrollan con mayor tamaño y complejidad en la parte inferior del $a q s u$, una prenda femenina de origen prehispánico que actualmente se sigue usando de forma ocasional (Figura 3) (Cereceda 2018: 501)7. Aunque originalmente envolvía todo el cuerpo, hoy es en una especie de manto, formado por dos piezas cosidas a la altura de la cintura, que cubre la espalda y las caderas de las mujeres. Se lleva encima de una almilla ${ }^{8}$ y se sujeta en los hombros con prendedores y en la cintura con una faja (Figura 4);

7 En época prehispánica el aqsu era una tela cuadrada o rectangular grande, habitualmente formada por dos piezas cosidas por el medio, que envolvía el cuerpo de la mujer de un costado al otro, cubriéndola desde el cuello hasta los tobillos. Se sujetaba en los hombros con prendedores de metal (topos) y quedaba amarrado a la cintura con una faja tejida (Dransart 1992: 146). Aunque su uso ha permanecido en algunas comunidades indígenas durante la época colonial, siendo la vestimenta de la “india común” (Money 1983: 188), y hasta la actualidad, a lo largo del tiempo se ha ido reduciendo en sus dimensiones y se ha complementado con otras prendas (Arnold 2018b: 304-313).

8 Camisa o vestido amplio de color negro o pardo que cubre la parte superior del cuerpo y los brazos, en el caso de los hombres, y que llega hasta debajo de las rodillas, en el caso de las mujeres. 
quedando en la parte superior e inferior las áreas figurativas con los diseños tejidos descritos (pallay), separados por un espacio de color negro o marrón liso (pampa) (Cereceda et al. 1993: 19-20).

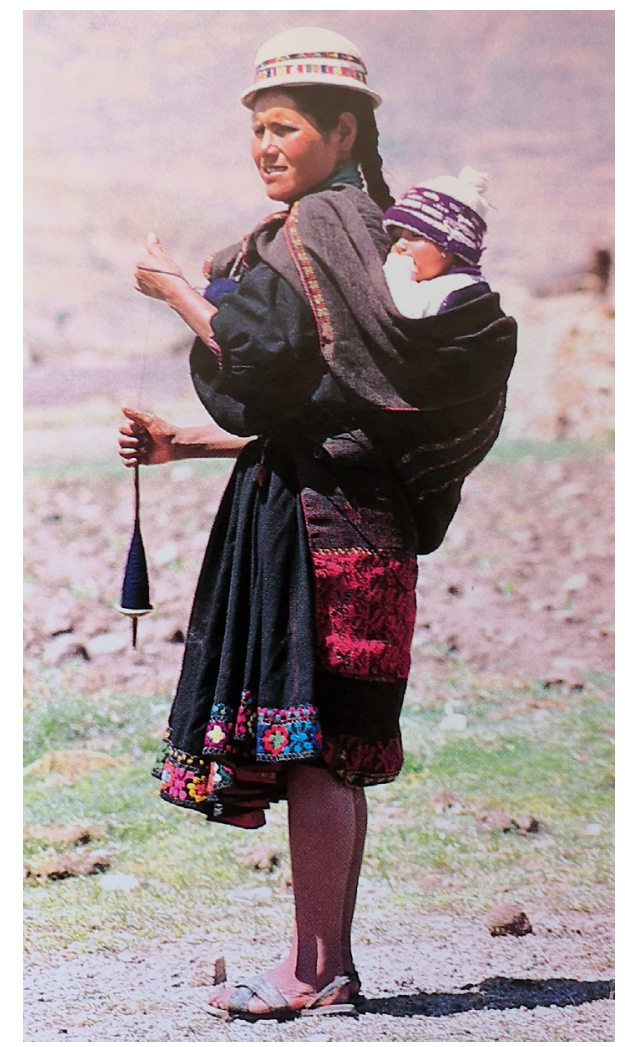

Figura 3. Mujer jalq'a vistiendo el aqsu sobre la almilla y cargando el niño en la lliklla (Cereceda et al. 1993: Ilustración 11).

A día de hoy, estos diseños son bien conocidos fuera de las comunidades jalq'a y del área cultural descrita: forman parte de muchas de las colecciones de los museos del país y se han convertido en un elemento atractivo para el turismo de Sucre, así como una fuente de inspiración para artistas contemporáneos ${ }^{9}$. Además, en el año 2020 se inició el proceso para declarar a "los conocimientos, las técnicas y las prácticas asociadas a los tejidos jalq'a" Patrimonio Cultural Inmaterial del municipio de Sucre, y poder postular al título conferido por la $\mathrm{UNESCO}^{10}$.

9 Ejemplos de proyectos artísticos inspirados en los diseños jalq’a: https://www.behance.net/gallery/28690141/ Khurus-Tipografia-ilustraciones-y-patterns (tipografía), https://vimeo.com/99895897 (animación), https:// ivntres.medium.com/welcome-to-ukupacha-d80cc4a02163 (diseño gráfico), https://vistelacalle.com/623969/ repasamos-el-desfile-epson-bolivia-organizado-por-vistelacalle-la-espina/ (moda), https://www.paginasiete.bo/ cultura/2015/11/1/cecilia-wilde-seduce-corea-obras-sobre-tejidos-jalqa-75435.html (pintura).

10 Para más información, puede consultar el siguiente enlace: https://correodelsur.com/local/20200107_municipio-alista-ley-de-patrimonio-para-los-tejidos-jalq-a.html 


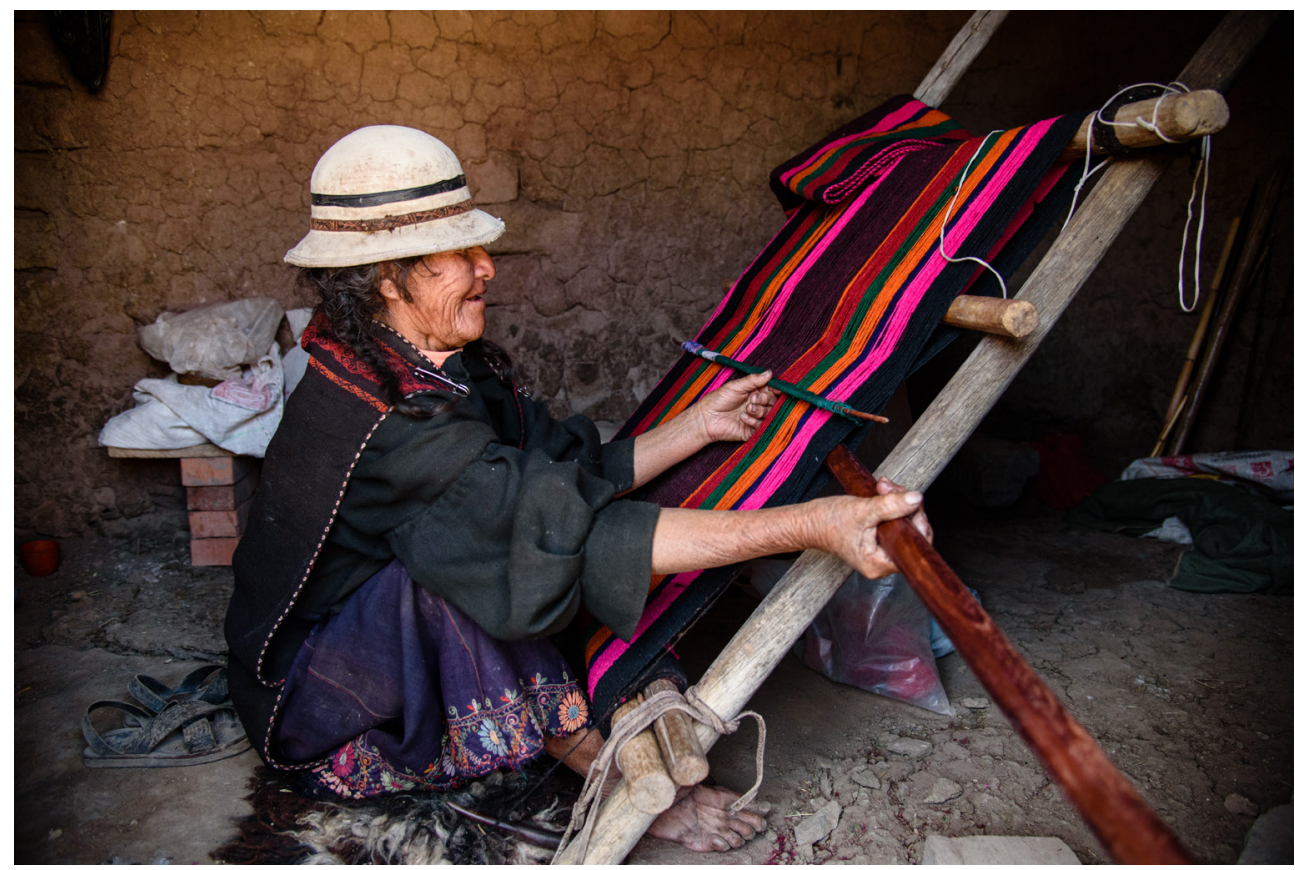

Figura 4. Ángela Aguilar tejiendo un tapiz en Maragua. Viste el aqsu encima de la almilla, sujetado en los hombros con imperdibles y amarrado en la cintura (fotografía de Michael Benanav).

En cuanto a los rasgos propios de los diseños tejidos jalq'a, destaca la dificultad de lectura y comprensión que las tejedoras crean al recurrir a colores poco contrastados y disponer las figuras de forma que se confunden fácilmente con el fondo. Se trata de un desorden intencionado: chaqrusqa kanantian, explican las tejedoras sobre sus pallay, "tiene que ser desordenado" (Cereceda 2016: 242). Este espacio confuso y oscuro está lleno de khurus -extraños animales de aspecto fantástico-, figuras del supay -del demonio o diablo- y almas de muertos. Sin embargo, lejos de ser una asimilación de la idea cristiana del infierno, el espacio que evoca el imaginario jalq'a es un espacio de vida, un lugar habitado por todo tipo de seres, animales libres y silvestres, entidades anímicas, demonios y dioses antiguos, seres que pertenecen o bien a un mundo interior ( $u k h u$ pacha) o a un tiempo anterior (chullpa $)^{11}$, pero no por seres humanos (Cereceda 2019a). Asimismo, es un espacio generador de vida, de abundancia y renovación (Martínez 1983: 86; Lanata 2007: 111; Cereceda 2019a: 357), lo cual concuerda, a su vez, con su connotación femenina (Flores Ochoa en Lanata 2007: 111). Es a través de este espacio creado por las tejedoras, como veremos a continuación, que las comunidades jalq'a expresan su identidad y construyen su etnicidad.

11 Con el término genérico chullpa los habitantes de las comunidades indígenas y campesinas de los Andes bolivianos se refieren a una humanidad diferente y extinta, anterior a la actual, así como a los restos materiales que son considerados sus vestigios (Cruz 2020: 376). Según las concepciones actuales de las comunidades jalq'a esta humanidad forma parte del mundo de lo interior o $u k h u$ pacha (Cereceda 2019a: 353). 


\section{Los jalq’a, la vestimenta como distintivo étnico}

La vestimenta tradicional jalq'a, como es el caso de muchos otros grupos indígenas de la región andina, es hoy un distintivo étnico bien reconocido. Ponerse la almilla y los calzones blancos con una franja negra en la manga, la lliklla ${ }^{12}$ oscura amarrada a la cintura y el chumpi ${ }^{13}$ colorido, en el caso de los hombres, y la almilla y la lliklla negra con bordado de flores, agarrados con el chumpi, y el aqsu con el diseño tejido del ukhu pacha, en el caso de las mujeres, identifica a las personas como jalq'a y los distingue de las comunidades vecinas (Cereceda et al. 1993: 15-19).

Si bien los textiles jalq'a más antiguos conservados son de finales del siglo XIX, la iconografía por la cual se distinguen los diseños actuales se ha ido desarrollando tan solo a lo largo de las últimas décadas, y especialmente a raíz del "Programa de Renacimiento del Arte Indígena", llevado a cabo por la fundación ASUR desde la década de los años $80^{14}$. A lo largo de este tiempo, el diseño tejido se ha vuelto desordenado y han ganado en protagonismo las representaciones de khuru, supay y almas de muertos, mientras que otros motivos, como rombos, arcos, animales o figuras humanas, característicos de los diseños más antiguos, han ido desapareciendo (Cereceda 2018: 502-503). De hecho, se trata de un proceso de definición intrarregional, donde las tejedoras de los diferentes grupos étnicos del entorno van acentuando, sobre todo en los diseños de los aqsu, su estilo particular (Cereceda 2019a: 257). De esta manera no sólo refuerzan visualmente su identidad étnica, sino también participan, de forma activa y a través de los tejidos, en un proceso de etnogénesis que está en pleno desarrollo (Cereceda 2018: 514-516).

Por otro lado, la vestimenta jalq'a y los supay pallay presentan a las personas como jalq'a en un sentido más amplio que el local, por medio de su exposición en los museos, y especialmente a través del Museo de Arte Indígena en Sucre, conocido como Museo ASUR (Antropólogos del Surandino). Situado en el casco histórico de la ciudad, en la zona emblemática de La Recoleta, el museo muestra colecciones textiles de las tres regiones étnicas más cercanas a la ciudad, entre ellas, las de jalq'a; así como objetos relacionados con la danza y la música, los rituales, y algunos materiales arqueológicos. Por la sencillez de los espacios y del diseño de exposición, permite al visitante explorar los objetos expuestos sin distracciones e imaginarse su uso en la vida cotidiana: junto a los textiles expuestos, hay maniquíes vestidos con las ropas tradicionales que parecen estar en movimiento, y en algunos rincones se escuchan grabaciones de la música tradicional de esta región. Además, hay un espacio reservado para una tejedora a la que se puede observar tejer, y apreciar el tiempo y esfuerzo que requiere la elaboración de los diseños.

A día de hoy, además de ser uno de los principales hitos turísticos de Sucre, el museo sigue colaborando con las comunidades, tanto para conservar sus creaciones

12 Manta amplia de forma cuadrada o rectangular que las mujeres usan a modo de capa para cubrir sus hombros y la espalda, así como para llevar niños pequeños o cargar cosas (ver Figura 3).

13 Faja tejida que se usa a modo de cinturón.

14 En el marco de este proyecto destacan los trabajos realizados por Verónica Cereceda sobre la iconografía de los tejidos jalq'a, donde analiza el origen y el desarrollo de los motivos que conforman los diseños (p.ej. 2016, 2018, 2019a), y sobre los cambios en las prácticas y la conceptualización de los diseños en las diferentes comunidades (p.ej. Cereceda et al. 1993). 
como para presentarlos y venderlos a los visitantes ${ }^{15}$. También gracias al museo, algunas tejedoras han podido viajar a Estados Unidos y Europa para representar a sus comunidades y su cultura (Eversole 2006: 949-950). Teniendo en cuenta que "[...] hasta hace bien poco, la relación de las comunidades indígenas con los museos parece haberse limitado al de objeto expositivo o de estudio, es decir, a un papel meramente pasivo" (Burón 2019: 25-26), podemos destacar, por lo tanto, el papel activo que los jalq'a asumen en la presentación de su identidad, incluso en la constitución de su propia etnicidad, a través del proceso de creación e innovación visual de sus diseños tejidos en el marco del programa de recuperación textil y la exposición de su vestimenta en el espacio del museo.

\section{La mujer tejedora, la elaboración del tejido}

Profundizando en la importancia que tiene la vestimenta tradicional en la interacción social, circunscrita a la comunidad y los individuos que la elaboran y usan, por ejemplo, el tejido y los diseños tejidos se nos presentan como algo más que distintivos étnicos. Como señala Rosalía Martínez, para los jalq'a "los tejidos se encuentran en relación con la dimensión social de la feminidad” (Martínez 2008: 34). Saber tejer es una cualidad reconocida de la mujer adulta y un requisito para poder cantar en público, una de las principales acciones que marcan el paso de niña a joven soltera en las comunidades de la región (2008: 31-34). En este sentido, la actividad del tejer no puede entenderse como algo limitado al conjunto de prácticas y técnicas que se despliegan en torno al telar: forma parte de dinámicas de vida más amplias que no sólo caracterizan la elaboración textil.

Al principio, las niñas aprenden las actividades del tejer observando a otras mujeres de su familia, y a medida que la complejidad de las técnicas que emplean, así como de las piezas que elaboran, aumenta, el resto de la comunidad de tejedoras se convierte igualmente en un punto de referencia (Cereceda 2018: 512). Recordamos que es en el aqsu donde los supay pallay, los diseños tejidos que muestran el $u k h u$ pacha, el mundo de adentro, adquieren su mayor desarrollo, y que estas imágenes definen "el estatuto de ser mujer" (Cereceda 2016: 262). Pero si bien parte del reconocimiento social de una tejedora viene de la calidad y originalidad que muestra en estos diseños (Martínez 2008: 13), también resulta importante la competencia técnica que manifiesta al tejer. El aqsu es la prenda más complicada de elaborar y la última que las niñas aprenden a hacer, ya que su "realización necesita de una gran maestría técnica y artística así como el conocimiento cabal de los códigos visuales que definen la identidad del grupo" (Martínez 2008: 32).

La mayoría de las prendas elaboradas por las mujeres jalq'a, entre ellas el aqsu, están tejidas en un telar vertical y en cara de urdimbre, de manera que los hilos de la urdimbre constituyen la cara visible de la pieza y el diseño se produce por el contraste entre los hilos longitudinales, formando parte, por lo tanto, del mismo tejido (Figura 5). Además, utilizan la técnica de urdimbres complementarias para tejer prendas como el aqsu, más complicada de realizar que otras, como el doble tejido,

15 Es interesante señalar que el museo fue dirigido inicialmente a visitantes campesinos, con la idea de registrar el proceso de recuperación textil y poner en contacto diferentes áreas originarias y tejedoras de otros departamentos (Cereceda 2019b). 
que se usa para tejer los chumpi o diseños en bandas en otros tejidos (Desrosiers 2013: 480-481). Como argumenta Cassandra Torrico para un grupo cercano a la región jalq'a, los Macha (Norte de Potosí):

"La competencia técnica para tejer un aksu es un marcador social de la feminidad y la adultez para las niñas que se acercan a la mayoría de edad. Se ven presionadas a aprender a tejer y a mostrar su competencia técnica en sus aksus, y así construir su reputación como parejas aptas para el matrimonio" (Torrico 2014: 197).

De esta manera, a medida que las niñas avanzan en su "camino de aprendizaje" como tejedoras (Arnold y Espejo 2013: 313-316), no sólo aprenden a tejer piezas cada vez más complicadas, adquiriendo nuevas habilidades y aplicando técnicas más difíciles, sino también construyen progresivamente su identidad social (Torrico 2014: 211).

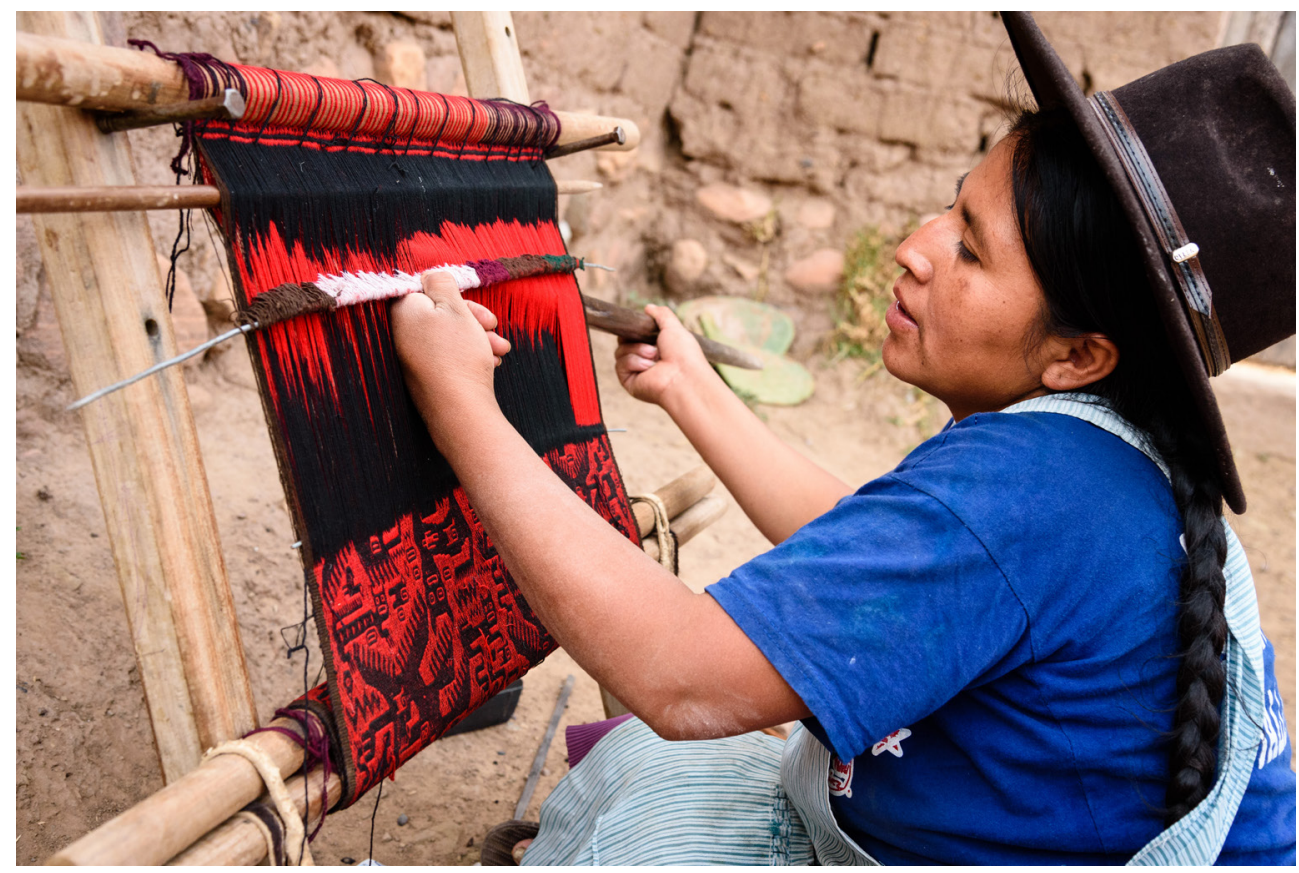

Figura 5. Juliana Choque tejiendo un aqsu en el telar vertical en Potolo (fotografía de Michael Benanav).

Los diseños de los aqsu son el resultado de la imaginación de la tejedora, de su modo de pensar y acercarse al mundo de abajo y de adentro, de lo salvaje e indomable, del supay y otros seres no-humanos, un mundo asociado a la vida y la fecundidad, y, por lo tanto, propio del ámbito femenino. En el aqsu materializan este mundo, lo hacen visible y lo convierten en un distintivo que no sólo establece su feminidad, sino también la posición femenina que han elegido los grupos de esta región para definir su identidad (Martínez 2001: 140-141; Auza 2010: 135-140). 
Por otra parte, cabe destacar que la elaboración textil no es, en este caso, una actividad a cargo de especialistas, sino algo llevado a cabo por las mujeres de la comunidad en un contexto social (Cereceda 2018: 512), incluso como parte de la vida cotidiana. Hoy en día, este contexto social, sin embargo, no se limita a la familia y la comunidad de las tejedoras: con el desarrollo del turismo en la región y la comercialización de los tejidos, las tejedoras también se insertan en las dinámicas de relación que estos nuevos contextos, propios del mundo globalizado, suponen ${ }^{16}$. Con la venta de los tejidos en las tiendas de Sucre y los tours turísticos ha aparecido un nuevo público y usuario final de los productos elaborados por las tejedoras, lo cual ha supuesto cambios, a su vez, en la conceptualización y realización de las piezas. Por ejemplo, convierte la elaboración textil artesanal en una actividad económica que involucra a personas antes excluidas, en este caso las mujeres, en el turismo y el trabajo remunerado, lo cual afecta, a su vez, a las dinámicas familiares (Eversole 2006: 950; Fernández 2006: 148, 160). Por otro lado, implica que el textil tradicional, pensado como prenda de vestir, se convierta en un souvenir, sin su significado y contexto de uso tradicional. Esto tiene consecuencias materiales muy directas: las tejedoras recurren a técnicas de elaboración más sencillas para elaborar piezas que, si bien son de menor calidad, resultan más económicas y más atractivas para la venta a turistas (Desrosiers 2012: 8) (Figura 6).

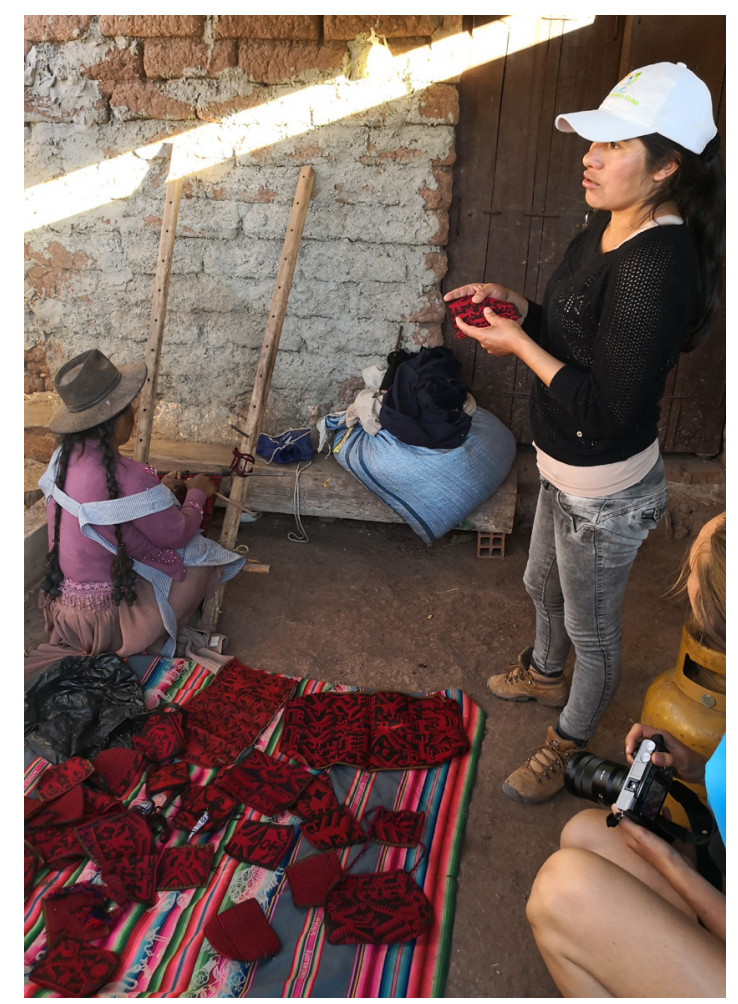

Figura 6. Turista frente a un puesto de venta de artesanías jalq'a (fotografía de la autora).

16 Un ejemplo de investigación que observa los retos y las oportunidades que se les presentan a las mujeres tejedoras en un contexto similar puede encontrarse en Celigueta y Martínez (2020). 
Asimismo, el reconocimiento y la valoración que han experimentado los tejidos jalq'a a lo largo de las últimas décadas también han situado a las tejedoras en medio de dinámicas políticas nacionales e internacionales. La preparación de la postulación de los tejidos jalq'a para ser reconocidos Patrimonio Cultural y Material de la $\mathrm{Hu}$ manidad (UNESCO), por ejemplo, puede entenderse como una consecuencia directa del contexto político que favorecía, durante el gobierno de Evo Morales, la visibilización de los "pueblos campesinos originarios", y la "fiebre" por la patrimonialización (Bigenho y Stobart 2018: 1329) que ha experimentado Bolivia desde entonces. Sin embargo, esta forma de constitución de patrimonio no está ausente de conflictos, tanto por las implicaciones jurídicas que tiene, como por los intereses divergentes de las instituciones y personas interesadas en la patrimonialización. Cuestiones como la autoría de los diseños, la capacidad para protegerlos y reivindicar los derechos de propiedad ante usos indebidos crean un escenario de relaciones de poder en el cual las tejedoras tienen que hacerse presentes con voz y medios propios. Siendo esto un proceso que se está iniciando ahora, me parece importante prestar atención a cómo las tejedoras jalq'a negociarán su papel como autoras y productoras con las instituciones, organismos y empresas involucradas, y en qué medida los retos y las oportunidades que supone la introducción de la producción textil artesanal en el mercado turístico, les permitirá participar de forma activa en estas nuevas dinámicas.

Este conjunto de relaciones que se articulan en torno al tejido muestran, por lo tanto, que la importancia y el significado de la actividad del tejer solo se entienden en un contexto más general de la vida y cosmología andina, donde confluyen múltiples formas de relacionarse. Asimismo, expresan que la elaboración de las prendas tejidas aparece como una vía mediante la cual las mujeres jalq'a definen su posición en la vida familiar, en la comunidad e, incluso, en el ámbito político y económico nacional e internacional. A continuación, propongo profundizar en las relaciones que se generan entre los tejidos y las personas a partir de su uso como ropa, y argumentar por qué podemos pensar que el tejido en los Andes, además de crear etnicidad y definir la posición social de las personas, también es lo que los constituye como seres humanos y, particularmente, como runa.

\section{Runa, el uso de la ropa como envoltura}

La tradición de pensar sobre el ser humano, runa y jaqi $i^{17}$, ha sido una constante en la antropología de los Andes, preocupada por comprender la formación de la persona en términos sociales y anímicos, así como, más recientemente, la noción de lo humano según las cosmologías y categorías de pensamiento locales (Muñoz 2020a: 10-11). En el marco de estas reflexiones acerca de quiénes son y cómo son los humanos y no-humanos en los Andes ${ }^{18}$, se ha ido planteando que la persona es conformada, idealmente en equilibrio, por un cuerpo y una pluralidad de entidades anímicas, entre las cuales destaca el ánimu, un principio vital que es considerado la fuerza animadora de todos los seres. El cuerpo, por su parte, protege las entidades

\footnotetext{
Jaqi es el equivalente aymara al término quechua runa.

18 Cabe señalar la importancia de los trabajos de Marisol de la Cadena (p.ej. 2014), en los cuales reflexiona sobre la condición runa como algo que excede la idea de persona o humano, y que contempla la participación de seres no-humanos en su conformación ontológica.
} 
anímicas al envolverlos (La Riva 2005; Lanata 2007: 78-80); de hecho, “[...] parte de la literatura se ha esforzado en describir y comprender las nociones andinas de persona como series sucesivas de envoltorios corporales [...]" (Pazzarelli 2020: 97). En este sentido, se entiende que son las diferentes partes del cuerpo (como el corazón, los huesos y la piel, por ejemplo), las que se sobreponen a modo de envolturas concéntricas para contener las entidades anímicas (Arnold 2020: 182). Sin embargo, también se ha ido observando que el tener ánimu y un cuerpo es algo compartido por todos los seres animados, tanto humanos como no-humanos, y que lo que parece constituir a la persona específicamente como humana es, entre otras cosas, el tener un cuerpo vestido (Muñoz 2020b: 31), un cuerpo envuelto en capas de ropas tejidas.

En el marco de estas reflexiones, Denise Arnold (2020) ha propuesto pensar los tejidos como una envoltura más del cuerpo destinada a convertir los seres en personas humanas. Su punto de partida es que las prácticas de envolver y desenvolver (no sólo con tejidos, sino también con palabras, cantos y determinados rituales, por ejemplo) forman parte de procesos destinados a "convertir algo en persona", los cuales forman parte, a su vez, de "procesos aún mayores para asegurar la continuidad de la vida" (Arnold 2020: 166). Más concretamente, explica que las prácticas de envolver y desenvolver están dirigidas a contener y soltar, respectivamente, una potencia generativa: al envolver se busca contener la fuerza vital para animar y dotar de vida a un $\operatorname{ser}^{19}$, y al desenvolver se busca soltarla de nuevo; marcando así un ciclo de crecimiento y decaimiento. En este sentido, señalan Arnold y Yapita:

"En los Andes, el envolver un cuerpo en un textil es convertirlo en humano (jaqi). Los qaqachakeños se envuelven en textiles familiares desde el momento en que nacen hasta el día en que mueren y son devoradas por la tierra" (Arnold y Yapita 2018: 41).

A medida que el cuerpo es vestido, envuelto en capas textiles que actúan a modo de envoltura de las fuerzas que lo animan, la persona se constituye, por lo tanto, específicamente como ser humano. Esto es, a lo largo del ciclo vital, este "[...] largo y complicado proceso de creación de la persona" (Canessa 2020: 349), los tejidos aparecen como un elemento que contribuye a la formación de la persona: no sólo en términos sociales, como miembro de una determinada etnia o comunidad, sino también ontológicos, como persona humana. A partir de esta idea, y tomando como ejemplo el vestuario tradicional jalq'a, propongo pensar en el aqsu como una prenda-envoltorio que contribuye a la formación ontológica de las mujeres jalq'a como persona humana (runa).

Recordamos que el aqsu es la pieza más complicada de tejer y la última que se aprende a hacer. Además, el saber tejer está en estrecha relación con la consideración social de las mujeres, y saber tejer un aqsu se corresponde con el paso de la infancia a la adultez (Martínez 2008). Podemos pensar que, al vestir el aqsu, las mujeres no solo muestran sus habilidades como tejedoras y determinan su posición social en la comunidad, sino que también añaden una envoltura a su cuerpo que las constituye

19 Durante la infancia, por ejemplo, se considera que el ánimu aún no se encuentra bien adherido al cuerpo y puede salirse en determinados momentos o lugares. Como su pérdida causa problemas de salud e incluso puede provocar la muerte (La Riva 2005: 76), se envuelve a los bebés y niños en tejidos (como fajas, cintas o la liklla) para ayudar a mantener su ánimu o fuerza vital dentro del cuerpo. 
como runa ${ }^{20}$. Sin embargo, por la importancia simbólica de esta prenda en el ciclo vital de la mujer jalq'a, se puede pensar también como una envoltura que las constituye como esposas y madres ${ }^{21}$.

Llama la atención el comentario de Crescencia Toro, tejedora de la comunidad de Potolo: "Dicen que al Dios del cielo no le gustan los khurus: Dicen que a las que llevan supay pallay, Dios no las recibe" (Cereceda 2019a: 359). Cuando se viste el cuerpo de una difunta, en el marco de los rituales funerarios, de repente se hace necesario buscar otro aqsu, con formas geométricas o liso, para no dificultar la correcta despedida de la fallecida ${ }^{22}$.

Creo que el problema de vestir el aqsu en el encuentro post mortem con Dios no es solo que los motivos muestren el "infierno andino", tan diferente al cristiano (Cereceda 2016, 2018). En la cosmología regional, la muerte es entendida, igual otros momentos del ciclo vital, como una etapa de transición: la persona deja de formar parte de la comunidad de los vivos y, concretamente, de los runa, y se convierte a lo largo de los rituales en un muerto, un alma, como suele denominarse el cadáver y la sustancia anímica que sobrevive a la muerte (La Riva 2005: 64). De forma inversa a como sucede a lo largo de la vida, por lo tanto, en la muerte la persona tiene que dejar de ser runa y constituirse como muerto, un ser no-humano (Canessa 2020). Creo que así lo sugiere el testimonio de Crescencia cuando se refiere a la necesidad de buscar otro aqsu: la fallecida puede vestir un aqsu cuando emprende el camino al más allá, pero no el que ha contribuido, como estoy proponiendo, a su formación como runa, esposa y madre. Tiene que desenvolverse de este aqsu porque tiene que dejar de ser humana.

Pero algo más parece suceder cuando las mujeres visten el aqsu. Como observa Petrona Javier, de la comunidad de Marawa, "[...] Cuando van a la fiesta [las mujeres con estos maravillosos vestidos] no pueden acercarse a la iglesia. Si llegan a entrar, sus aqsu se vuelven puro humo" (Cereceda 2019a: 359). Si tenemos en cuenta que la iconografía propia del aqsu jalq'a muestra el $u k h u$ pacha, un mundo que se define por la vitalidad y fertilidad, esto es, fuerzas genésicas que emanan de los espacios profundos según la cosmología andina (Cereceda 2019a; Cruz 2016), podemos pensar que este testimonio resalta el hecho que el aqsu constituye a las mujeres como runa, esposas y madres, según sus propias categorías ontológicas; categorías que no coinciden con las de la doctrina cristiana, donde el poder creador y la fuerza vital proceden de Dios y el Espíritu Santo. De nuevo, parece ser que el problema no sólo es que los supay pallay aludan al infierno, o que su inspiración sea el demonio, sino que expresan ideas sobre la vida que son distintas a las de la doctrina cristiana.

Sin embargo, y a pesar de que parece una problemática de creencias, se trata de algo que no causa un conflicto de identidad. Hay espacios y momentos en los que

20 De forma similar lo sugiere Torrico para las mujeres macha, cuando concluye que para ellas el tejido no esconde a la persona, a un "yo" real interior (inner real self), sino que la persona que lo ha fabricado, la tejedora, está en el tejido y forma parte del mismo (Torrico 2014: 207). También es interesante señalar que Dransart (1992: 146) comenta, en el caso de las mujeres inca, que el aqsu se consideraba más que una simple prenda: era una parte integral de la persona que lo tejía.

21 Por sobrepasar el límite de espacio y el objetivo de este texto, no puedo incluir aquí una descripción de las normas de uso del aqsu o de las diferentes formas de llevarlo, si bien es necesario considerar estos aspectos en un futuro para continuar la reflexión presentada.

22 Sobre la importancia de la ropa en los rituales funerarios se puede consultar p.ej. Carter (1968), Van Kessel (1978), Harris (1983), Robin (2005). 
las mujeres visten el aqsu con los supay pallay, y otros en los que no. Quizás es un ejemplo de lo que Pablo Cruz describe como esta "constante capacidad de articular simultáneamente y fluidamente diferentes realidades" (Cruz 2016: 193), esto es, una forma de integrar categorías ontológicas distintas, vivirlas en paralelo, juntas, aunque no necesariamente revueltas ${ }^{23}$.

\section{Conclusión}

El tejido ha tenido y tiene a día de hoy una importancia fundamental para la vida cotidiana y ritual en los Andes, siendo probablemente una de las manifestaciones culturales, artísticas y tecnológicas más sofisticadas de esta región, y un medio de expresión de indudable valor.

Aquí he explorado, siguiendo líneas de investigación que actualmente se están desarrollando en la antropología andina, qué nos puede explicar el tejido sobre las personas cuando fijamos la atención en las relaciones que se generan en torno a éste, en la práctica del tejer y su uso como ropa. Concretamente, he presentado tres diferentes formas en las cuales pienso que podemos considerar que se constituye la persona, en términos sociales y ontológicos, a través del tejido en los Andes, tomando como ejemplo la vestimenta tradicional jalq'a y su particular estilo de diseño tejido. En primer lugar, he presentado la vestimenta jalq'a como un emblema étnico, con el cual los jalq'a se presentan y reivindican su identidad, tanto en el ámbito local como, a través del museo, a nivel nacional e internacional. A continuación, he señalado la importancia social del tejido dentro de la comunidad, prestando atención a su elaboración y las relaciones que se generan y expresan en torno a las prendas tejidas. En esta parte he destacado que la actividad del tejer está en estrecha relación con la feminidad y la posición social de la mujer en las comunidades jalq'a, así como en contextos sociales más amplios, propios del mundo globalizado y del turismo. Por último, he propuesto pensar el tejido jalq'a como una "envoltura generativa" (Arnold 2020), esto es, como una envoltura del cuerpo que contribuye a la formación de la persona como runa.

Profundizando en esta idea y exponiendo una reflexión en torno al aqsu como envoltura, he querido explorar si además de pensar que los tejidos y las ropas contribuyen a la formación de la persona al envolverla y desenvolverla, se puede considerar que determinadas envolturas, por cómo son, por la manera y por el momento en el cual envuelven a la persona, contribuyen a su formación de diferentes maneras. Como hemos visto, podemos pensar que el aqsu no sólo constituye a la persona como runa, sino también a la mujer jalq'a como esposa y madre; añadiendo, por lo tanto, matices o, siguiendo la retórica de las "series sucesivas de envoltorios corporales" (Pazzarelli 2020: 97), diferentes "capas" a la constitución de la persona, a las formas de sentirse y definirse, según las propiedades de las envolturas.

23 Manuel Gutiérrez ha criticado la interpretación de estos fenómenos como muestra de sincretismo y defiende que las diferentes tradiciones presentes en sociedades indígenas no sólo están claramente diferenciadas, sino que también cumplen diferentes funciones; por lo cual se corresponderían más bien a un hibridismo, o una heteoglosia, un "lugar de voces en oposición" (Gutiérrez 2014: 138), en lugar de una mezcla o creación nueva de tradiciones. 
De esta manera, la persona podría entenderse también en función del conjunto de capas, de la combinación particular de envoltorios corporales, que la conforman en cada momento. Además, teniendo en cuenta las implicaciones sociales y ontológicas de la elaboración y del uso de las prendas, podemos considerar que los cambios que se producen en los hábitos de vestir no sólo nos hablan de cambios sociales y económicos que se reflejan en la apariencia de las personas, sino también influyen en la forma de constituirse como tales. En este sentido, esta propuesta de interpretación, de pensar la persona a través del tejido, quiere invitar a profundizar en la reflexión sobre la práctica textil como parte de dinámicas de interacción más amplias que implican, al menos en la cosmología andina, a humanos y no-humanos, personas y tejidos, por igual.

\section{Referencias}

Allen, Catherine. 2020. "Inqaychus andinas y la animacidad de las piedras", en Andes. Ensayos de etnografía teórica, Óscar Muñoz Morán, ed., pp. 193-226. Madrid: Nola Editores. Arnold, Denise Y. 2018a. "Making Textiles into Persons: Gestural Sequences and Relationality in Communities of Weaving Practice of the SouthCentral Andes". Journal of Material Culture 23 (2): 1-22. https://doi.org/10.1177/1359183517750007.

—. 2018b. Los productos textiles de los Andes sur-centrales: Guía ontológica centrada en la región aymara-hablante. La Paz: Instituto de Lengua y Cultura Aymara, Instituto Francés de Estudios Andinos.

—. 2020. "Envolturas generativas. Procesos vitales en los Andes Meridionales", en Andes. Ensayos de etnografia teórica, Óscar Muñoz Morán, ed., pp. 163-192. Madrid: Nola Editores.

Arnold, Denise Y. y Elvira Espejo. 2013. El textil tridimensional: la naturaleza del tejido como objeto y como sujeto. La Paz: Instituto de Lengua y Cultura Aymara.

Arnold, Denise Y. y Juan de Dios Yapita. 2018 (1998). Río de vellón, río de canto: cantar a los animales, una poética andina de la creación. La Paz: Instituto de Lengua y Cultura Aymara.

Arnold, Denise Y., Elvira Espejo y Juan de Dios Yapita. 2007. Hilos sueltos: los Andes desde el textil. La Paz: Plural Editorial.

Auza Aramayo, Verónica. 2010. “Una mueca de feminidad jalq’a. Los cuerpos monstruosos en el tacto sublimado del textil". T'inkazos. Revista Boliviana de Ciencias Sociales 28: 131-142.

Bigenho, Michelle y Henry Stobart. 2018. "Grasping Cacophony in Bolivian Heritage Otherwise". Anthropological Quarterly 91 (4): 1329-1363. https://doi.org/10.1353/anq.2018.0067.

Bray, Tamara. 2009. "An Archaeological Perspective on the Andean Concept of Camaquen: Thinking Through Late Pre-Columbian Ofrendas y Huacas". Cambridge Archaeological Journal 19 (3): 357-366.

Bugallo, Lucila. 2016. "Wak'as en la puna jujeña. Lo fluido y lo fino en el diálogo con pachamama", en Wak'as, diablos y muertos: alteridades significantes en el mundo andino, Lucila Bugallo y Mario Vilca, comp., pp. 111-161. San Salvador de Jujuy: Editorial de la Universidad Nacional de Jujuy, Instituto Francés de Estudios Andinos.

Burón Díaz, Manuel. 2019. El patrimonio recobrado. Museos indígenas en México y Nueva Zelanda. Madrid: Marcial Pons. 
Canessa, Andrew. 2020. "Un carrusel de cosmologías: Giros ontológicos en el mundo andino”, en Andes. Ensayos de etnografía teórica, Óscar Muñoz Morán, ed., pp. 341-364. Madrid: Nola Editores.

Carlos Ríos, Eugenia. 2015. La circulación entre mundos en la tradición oral y ritual y las categorías del pensamiento quechua: en Hanansaya Ccullana Ch'isikata (Cusco, Perú). Tesis doctoral. Universitat Autònoma de Barcelona. https://ddd.uab.cat/pub/tesis/2015/hdl_10803_323103/ecr1de1.pdf.

Carter, William. 1968. "Secular Reinforcement in Aymara Death Ritual”. American Anthropologist 70 (2): 238-263.

Celigueta Comerma, Gemma y Mónica Martínez Mauri. 2020. “¿Textiles mediáticos? Investigar sobre activismo indígena en Panamá, Guatemala y el espacio Web 2.0". Revista Española de Antropología Americana 50: 241-252. https://doi.org/10.5209/reaa.70367.

Cereceda, Verónica. 2016. "En torno al supay andino: el aporte de lo visual a su interpretación”, en Wak'as, diablos y muertos: alteridades significantes en el mundo andino, Lucila Bugallo y Mario Vilca, comp., pp. 231-265. San Salvador de Jujuy: Editorial de la Universidad Nacional de Jujuy, Instituto Francés de Estudios Andinos.

—. 2018. "Imágenes tejidas del ukhu pacha: inquietudes planteadas a los etnohistoriadores y arqueólogos, desde la etnología”, en Interpretando huellas. Arqueología, Etnohistoria y Etnografía de los Andes y sus Tierras Bajas, María de los Ángeles Muñoz, ed., pp. 501517. Cochabamba: Grupo Editorial Kipus, Instituto de Investigaciones Antropológicas y Museo Arqueológico.

—. 2019a. "Antiguas pinturas rupestres y diseños étnicos en textiles actuales en la región jalq'a", en Culturas visuales indígenas y las prácticas estéticas en las Américas desde la antigüedad hasta el presente, Sanja Savkic, ed., pp. 349-366. Estudios Indiana 13. Berlín: Ibero-Amerikanisches Institut.

—. 2019b. "El Museo de Arte Indígena de la fundación ASUR. Una experiencia especial", Chungara. Revista de Antropología Chilena 51 (2): 239-251.

http://dx.doi.org/10.4067/S0717-73562019005001405.

Cereceda, Verónica, Jhonny Dávalos y Jaime Mejía. 1993. Una diferencia, un sentido: los diseños de los textiles Tarabuco y Jalq'a. Sucre: Antropólogos del Surandino (ASUR).

Cruz, Pablo. 2016. "Pensando en Supay o desde el Diablo. Saqra, paisaje y memoria en el espacio surandino", en Wak'as, diablos y muertos: alteridades significantes en el mundo andino, Lucila Bugallo y Mario Vilca, comp., pp. 171-200. San Salvador de Jujuy: Editorial de la Universidad Nacional de Jujuy, Instituto Francés de Estudios Andinos.

—. 2020. "Por la senda de los nuevos ancestros. Dinámicas de actualización ontológica en el espacio surandino (Salar de Uyuni, Bolivia)", en Andes. Ensayos de etnografía teórica, Óscar Muñoz Morán, ed., pp. 365-402. Madrid: Nola Editores.

De la Cadena, Marisol. 2014. "Runa. Human but not only". HAU: Journal of Ethnographic Theory 4 (2): 253-259. https://doi.org/10.14318/hau4.2.013.

Descola, Philippe. 2012. Más allá de naturaleza y cultura. Buenos Aires: Amorrortu.

Desrosiers, Sophie. 2012. "Can We Study Textiles from Other Cultures without Ethnocentrism? The Andes as a Case Study", en Textile Society of America13th Biennial Symposium Proceedings 674: 1-9. Washington D.C. https://digitalcommons.unl.edu/tsaconf/674.

- 2013. "El textil como matriz para el desarrollo de las artes plásticas en los Andes". Revista Española de Antropología Americana 43 (2): 477-514. http://dx.doi.org/10.5209/rev_REAA.2013.v43.n2.44020. 
Dransart, Penny. 1992. "Pachamama. The Inka Earth Mother of the Long Sweeping Garment", en Dress and gender. Making and meaning in cultural context, Ruth Barnes y Joanne B. Eicher, eds., pp. 145-163. Nueva York: Berg.

Eversole, Robyn. 2006. "Crafting Development in Bolivia". Journal of International Development 18 (7): 945-955. https://doi.org/10.1002/jid.1297.

Fernández, José Ernesto. 2006. “Comunidades indígenas, textiles y turismo. Un estudio de caso del programa textil de ASUR y las comunidades Tarabuco", en La Ruta Andina. Turismo y desarrollo sostenible en Perú y Bolivia, Annelou Ypeij y Anelies Zoomers, eds., pp. 147-167. Quito: Ediciones Abya-Yala, Instituto de Estudios Peruanos, Centro Bartolomé de Las Casas, Centro de Estudios y Documentación Latinoamericanos.

Gisbert, Teresa, Silvia Arze y Martha Cajías. 1987. Arte Textil y mundo andino. La Paz: Gisbert y Cía.

Gutiérrez Estévez, Manuel. 2014. “Otra vez sobre sincretismo”. ENDOXA: Series Filosóficas 33: 119-141. https://doi.org/10.5944/endoxa.33.2014.13557.

Harris, Olivia. 1983. "Los muertos y los diablos entre los laymi de Bolivia". Chungara. Revista de Antropología Chilena 11: 135-152.

Holbraad, Martin y Morten Axel Pedersen. 2017. The Ontological Turn. An Anthropological Exposition. Cambridge: Cambridge University Press.

La Riva González, Palmira 2005. "Las representaciones del animu en los Andes del sur peruano". Revista Andina 41: 63-88.

Lanata, Xavier 2007. Ladrones de sombra: el universo religioso de los pastores del Ausangate (Andes peruanos). Lima: Instituto Francés de Estudios Andinos.

Mannheim, Bruce y Guillermo Salas Carreño. 2015. “Wak'as: Entifications of the Andean Sacred", en The Archaeology of Wak'as: Explorations of the Sacred in the pre-Columbian Andes, Tamara Bray, ed., pp. 46-72. Boulder: University Press of Colorado.

Martínez, Gabriel. 1983. "Los dioses de los cerros en los Andes". Journal de la Société des Américanistes 69: 85-115.

-. 2001. "Saxra (diablo)/Pachamama; Música, tejido, calendario e identidad entre los jalq'a". Estudios Atacameños 21: 133-151. https://doi.org/10.22199/S07181043.2001.0021.00007.

Martínez, Rosalía. 2008. "Canto y feminidad entre los jalq'a y los tarabuco (Bolivia)". Revista Argentina de Musicología 9: 19-40.

http://ojs.aamusicologia.org.ar/index.php/ram/article/view/145/142.

—. 2018. "A propósito de las músicas indígenas andinas: sonidos para animar el mundo", en La música y los pueblos indígenas, Coriún Aharonián, coord., pp. 199-216. Montevideo: Centro Nacional de Documentación Musical Lauro Ayestarán.

Money, Mary. 1983. Los obrajes, el traje y el comercio de ropa en la Audiencia de Charcas. La Paz: Instituto de Estudios Bolivianos, Facultad de Humanidades, Universidad Mayor de San Andrés.

Muñoz Morán, Óscar. 2020a. "Una introducción. Seres relacionales: hacía una antropología de la fluidez desde los Andes", en Andes. Ensayos de etnografía teórica, Óscar Muñoz Morán, ed., pp. 7-46. Madrid: Nola Editores.

-. 2020b. "Ánimu, cuerpo y movimiento en los sueños andinos". Temas Americanistas 45: 28-48. https://revistascientificas.us.es/index.php/Temas_Americanistas/article/ view/15293/13413

Pazzarelli, Francisco. 2020. "Parte-pastor. Notas sobre pastoreo y predación en los cerros jujeños (Andes Meridionales, Argentina)", en Andes. Ensayos de etnografía teórica, Óscar Muñoz Morán, ed., pp. 85-113. Madrid: Nola Editores. 
Raas, Kimberley. 2020. "De humanos y no humanos. Reflexiones y debates actuales en la antropología de los Andes”. Revista Chilena de Antropología 42: 95-111. https://revistadeantropologia.uchile.cl/index.php/RCA/article/view/60486

Rivera, Juan Javier. 2018. "Humanos y no humanos en la música indígena de los Andes contemporáneos", en Humanidad. Categoría o condición. Un viaje antropológico, Montserrat Ventura, Josep Lluís Mateo y Montserrat Clua, eds., pp. 201-214. Barcelona: Edicions Bellaterra.

Robin Azevedo, Valérie. 2005. "Caminos a la otra vida. Ritos funerarios en los Andes peruanos meridionales”, en Etnografías del Cuzco, Antoinette Molinié, comp., pp. 47-68. Cuzco: Centro de Estudios Regionales Andinos Bartolomé de Las Casas, Instituto Francés de Estudios Andinos, Labethno.

Silverman, Gail. 1998. El tejido andino: un libro de sabiduría. México: Fondo de Cultura Económica.

Torrico, Cassandra. 2014. "Technical Competence in Weaving as a Means of Distinction among Young Macha Women from Tumaukuri, Northern Potosí, Bolivia”, en Textiles, Technical Practice and Power in the Andes, Denise Arnold y Penelope Dransart, eds., pp. 195-215. Londres: Archetype Publications.

Van Kessel, Juan. 1978. "Muerte y ritual mortuorio entre los aimaras". Norte Grande 6 (2): 77-93. 